\title{
Central Projections of Fibers in the Auditory and Tensor Nerves of Cicadas (Homoptera: Cicadidae)
}

\author{
D.W. Wohlers*, J.L.D. Williams*, F. Huber*, and T.E. Moore** \\ * Max Planck Institut für Verhaltensphysiologie, Seewiesen, Bundesrepublik Deutschland \\ ** The University of Michigan, Museum of Zoology, Ann Arbor, Michigan, USA
}

\begin{abstract}
Summary. The auditory and tensor nerves of cicadas are mixed nerves containing both afferent and efferent elements. In 17-year cicadas, and in Okanagana rimosa, the auditory nerve contains afferents from body hairs, from the detensor tympani-chordotonal organ, and some 1300-1500 afferents from the hearing organ. Within the fused metathoracic-abdominal ganglionic complex the receptors from both the auditory and tensor nerves form a neuropilar structure that reveals the metameric organization of this complex. A few fibers run anteriorly, projecting into the meso- and prothoracic ganglia. Within the ganglionic complex a division of auditory nerve afferents into a dense intermediate and a more diffuse ventral neuropile is observed. In addition, a dorsal motor neuropile is outlined by arborizations of the timbal motor neuron. This neuron is one of several efferent cell types associated with the auditory nerve, and there is an indication that several efferent fibers innervate the timbal muscle. There is anatomical evidence for a possible neuronal coupling between the bilaterally symmetrical large timbal motor neurons. In general, central projections from the auditory and tensor nerves support evidence of a structural "layering" within the CNS of insects.
\end{abstract}

Key words: CNS projections - Auditory nerves - Tensor nerves - Cicada Insects.

Cicadas are well-known for their production of loud sounds used in intraspecific communication (Alexander, 1967). In most species only the males have developed sound-generating systems; both sexes possess hearing organs.

The morphology of the auditory organs has been investigated by Vogel (1923), Michel (1975), and Young and Hill (1977). They show that each ear contains more

Send offprint requests to: D.W. Wohlers, Abt. Huber, Max Planck Institut für Verhaltensphysiologie, 8131 Seewiesen, Federal Republic of Germany 
than 1000 scolopidia; their sensory axons form part of the auditory nerve which enters the fused metathoracic-abdominal ganglionic complex (Pringle, 1954; Vasvary, 1966; Simmons and Young, 1978). In some species studied, the auditory nerve carries both the sensory fibers from the auditory organ and the motor innervation to the timbal muscle (Young, 1972; Simmons and Young, 1978). In others, the large timbal motor neuron is found in a separate timbal nerve (Pringle, 1954).

This paper offers a first description of the central projections of sensory fibers in the auditory and tensor nerves in four cicada species of the subfamily Tibicininae. Also revealed is the detailed structure of the motor neuron of the timbal muscle (Simmons, 1977) and other neurons with fibers in the auditory and tensor nerves.

\section{Materials and Methods}

Adult periodical (17-year) cicadas Magicicada septendecim Linnaeus, M.cassini Fisher, and $M$. septendecula Alexander and Moore were collected in June of 1978 from Botetourt Co., Virginia and Okanagana rimosa Say (life-cycle 8-10 years) in July from Montmorency Co., Michigan. Both males and females were caged on potted cistena plum shrubs (Prunus sp.) where they could feed and were transported to the laboratory in Ann Arbor, Michigan for anatomical study. Auditory or tensor nerves were cut immediately anterior to the sternal canal (Vasvary, 1966), and cells with axons in this region of the nerves were stained centrally by the cobalt axonal-filling method described by O'Shea et al. (1974). We used a $5 \%$ cobaltous chloride solution with diffusion times of $12-20 \mathrm{~h}$ at $6^{\circ} \mathrm{C}$. Nervous tissue was removed and placed in $10 \mathrm{ml}$ of insect saline (Fielden, 1960) containing 3 drops of concentrated ammonium sulphide. When the nervous elements containing cobalt ions turned dark, the tissue was rinsed in insect saline for $20 \mathrm{~min}$, fixed for $2 \mathrm{~h}$ in Bouin's fluid, dehydrated, cleared in methyl-salicylate, and mounted in Canada balsam.

Wholemount preparations were first photographed, then intensified, using the improved Timm's modification described by Bacon and Altman (1977), and embedded in Araldite. Thick sections (30$40 \mu \mathrm{m}$; horizontal, sagittal, transverse) were cut and photographed individually. Single cells and neuropilar structures were reconstructed using a Wild M20 microscope equipped with a drawing tube.

To study the general features of the CNS and the peripheral pathways of nerves, whole animals were embedded in celloidin. Thick sections $(150 \mu \mathrm{m})$ were cut and stained with hematoxylin (Harris). Photographs of some sections were taken and nerve pathways were reconstructed.

\section{Results}

\section{General Structure of the Central Nervous System}

The general anatomy of the CNS is similar in all 17-year cicadas and 0 .rimosa (Fig. 1). As found in Cystosoma saundersii (Simmons and Young, 1978), the mesothoracic ganglion is distinctly separated from the fused metathoracicabdominal ganglionic complex (Fig. $1 \mathrm{a}$ and $\mathrm{b}$ ). In all species studied here, a small abdominal nerve, which has not been described previously, was found between the large abdominal nerve and the auditory nerve (Fig. $1 \mathrm{~b}$ and $\mathrm{c}$, san).

\section{Peripheral Innervation of the Auditory and Tensor Nerves}

The auditory nerve leaves the metathoracic-abdominal ganglionic complex from a position antero-dorsal to the abdominal nerves and runs posteriorly beside the large and small abdominal nerves (Fig. $1 \mathrm{~b}$ and c) through the sternal canal (Fig. 2, 

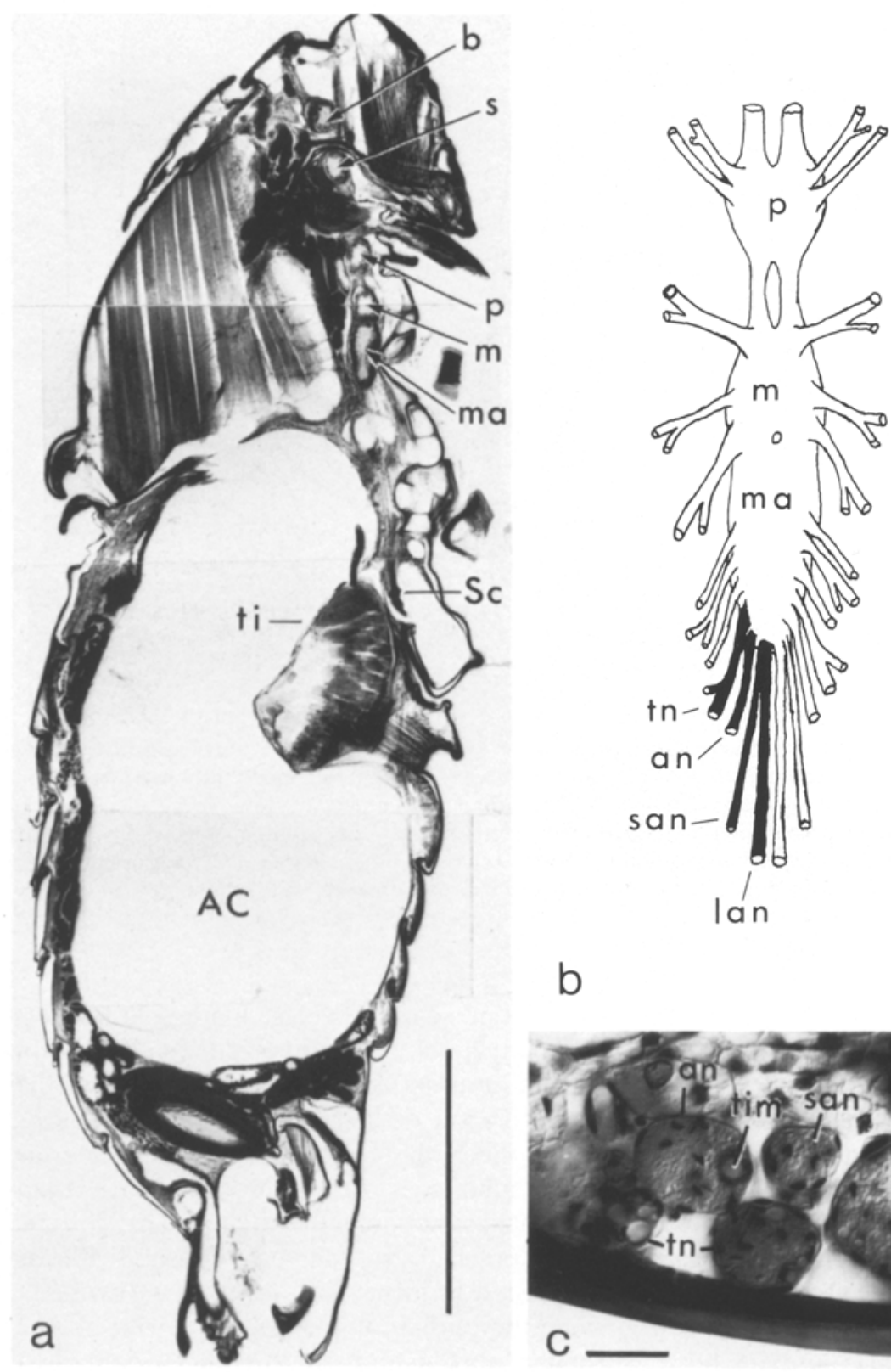

$\mathrm{b}$

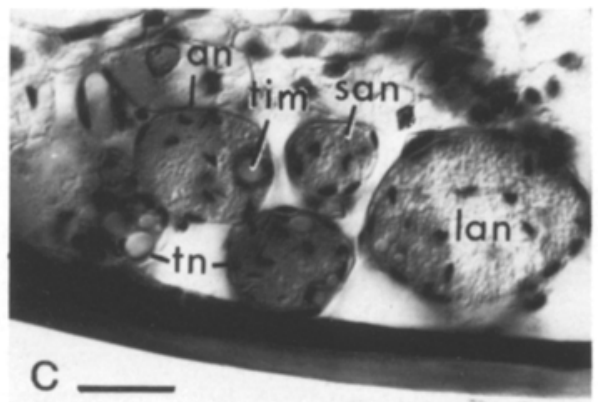

Fig. 1. a Sagittal section through a male $M$. septendecim showing the position of the condensed nervous system. b Outline of the thoracic and abdominal ganglia and the origin of the nerves used in this study. Transverse section of the nerves outlined in black in $\mathrm{b}$. Labels: $A C$ air chamber; an auditory nerve; $b$ brain; lan large auditory nerve; $m$ mesothoracic ganglion; $m a$ metathoracic-abdominal ganglionic complex; $p$ prothoracic ganglion; $s$ subesophageal ganglion; san small abdominal nerve; $S c$ sternal canal; ti timbal muscle; tim timbal motor neuron; $t n$ tensor nerve. Scale: a $5 \mathrm{~mm}$; c $50 \mu \mathrm{m}$. Arrow indicates anterior $(a, b)$ and dorsal (c) 


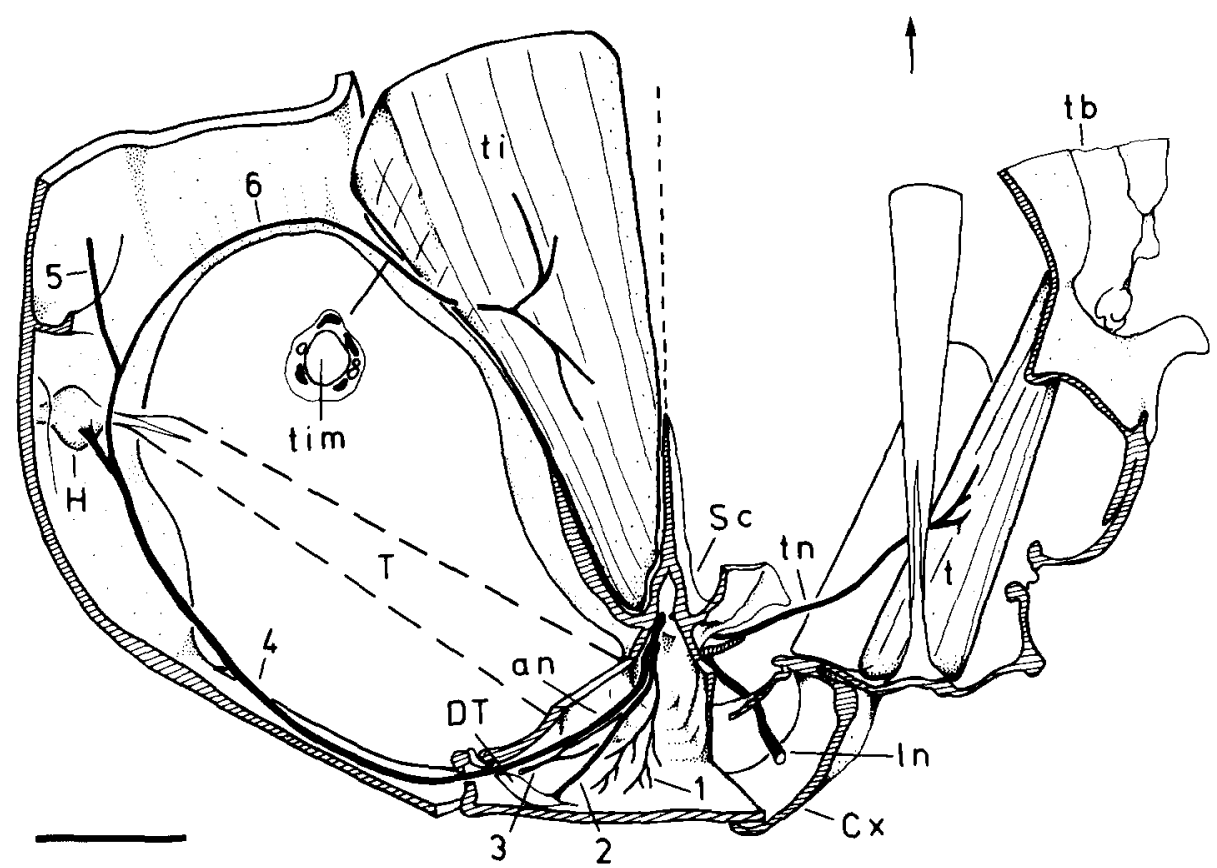

Fig. 2. Partial transverse reconstruction from a portion of a male $M$. cassini, viewed posteriorly. The left side shows the peripheral innervation of the auditory nerve; the right side shows the innervation of the tensor muscle. Inset: Transverse section through the distal portion of auditory nerve branch 6 showing the timbal motor neuron ( $\mathrm{tim}$ ) and three other axons. Labels: $1-6$ auditory nerve branches; $C x$ metacoxa; $D T$ detensor tympani-chordotonal organ; $H$ hearing organ; $I n$ leg nerve; $t$ tensor muscle; $t b$ timbal; other labels as in Fig. 1 . Scale: $1 \mathrm{~mm}$. Arrow indicates dorsal

left). Within the sternal canal the auditory nerve (an) divides, giving a branch ( $l$ ) which, on leaving the canal, innervates body hairs. It continues, subdividing again (2) to innervate the detensor tympani-chordotonal organ (Young, 1975) and the detensor tympani-muscle (3). The main branch of the auditory nerve (4) turns peripherally and laterally to run along the body wall, following the posterior surface of the tympanum. It again subdivides near the tympanal organ (Simmons and Young, 1978). One branch containing the auditory fibers runs anteriorly to the hearing organ; another branch (5) runs dorsally and subdivides at least twice (the peripheral innervation of these branches is currently being studied).

Branch 6 turns inward to innervate the timbal muscle (Young, 1972; Young and Hill, 1977). Consequently the proximal portion of the auditory nerve contains a number of efferent axons and sensory fibers from at least three sensory structures, one of which is the hearing organ.

The tensor nerve leaves the metathoracic-abdominal ganglionic complex from a position latero-ventral and anterior to the auditory nerve (Fig. $1 \mathrm{~b}$ ). It does not pass through the sternal canal, but instead turns laterally in the first abdominal segment to innervate various muscles (Fig. 2, right) and sensory structures as shown by Simmons and Young (1978). 

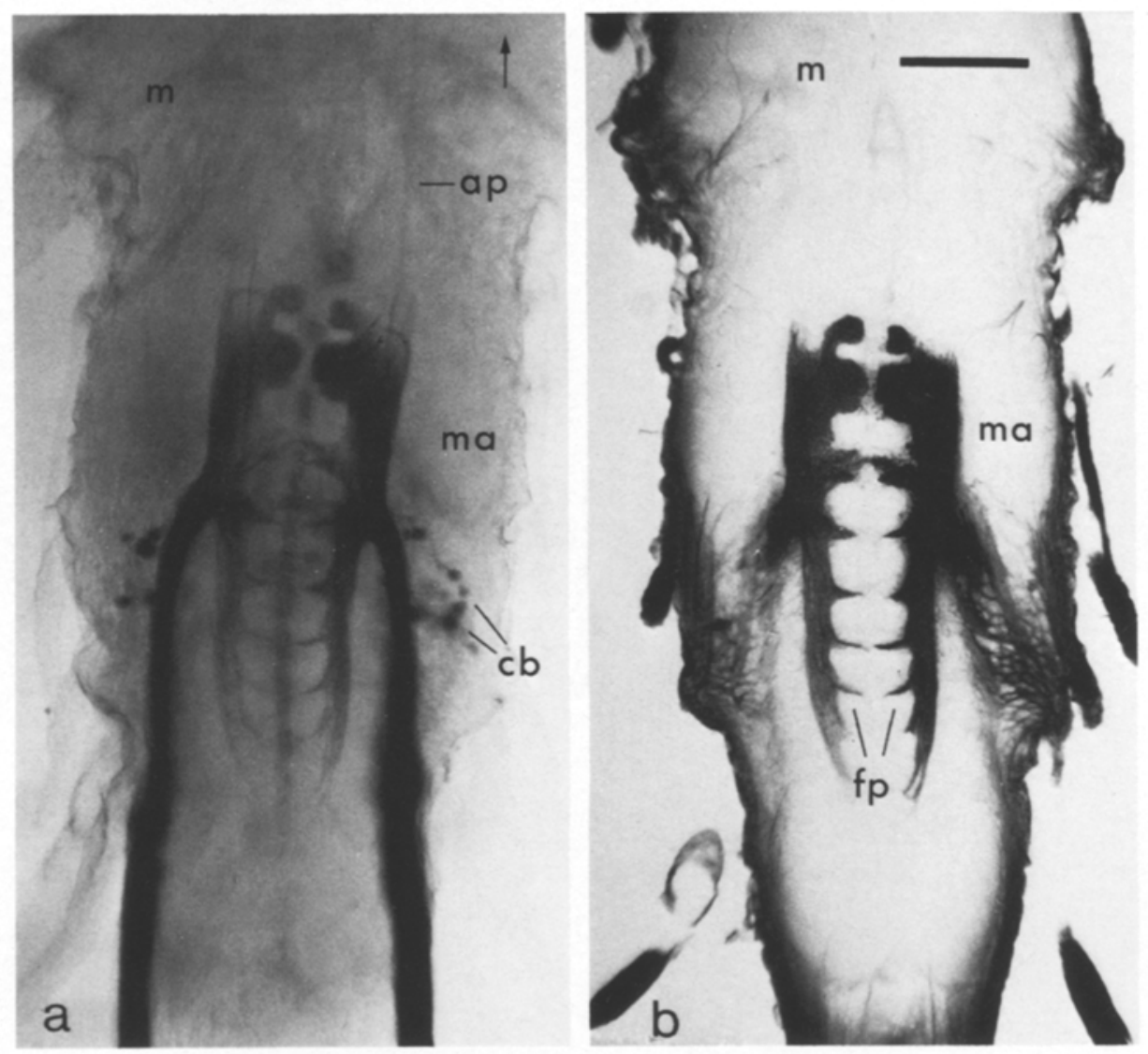

Fig. 3. Central projections of cobalt-stained elements from the auditory nerve in the metathoracicabdominal ganglionic complex. a Horizontal view of a wholemount. b Horizontal section of the same preparation after Timm's intensification. Note the metameric organization. Labels: $a p$ anterior projections to the mesothoracic ganglion; $c b$ cell bodies; $f p$ finger-like projections to intermediate neuropile; other labels as in Figs. 1 and 2. Scale: $200 \mu \mathrm{m}$. Arrow indicates anterior

\section{Central Projections of Sensory Fibers in the Auditory Nerve}

The distribution of sensory fiber projections from the auditory nerve into the metathoracic-abdominal ganglionic complex reflects the metameric organization within this complex (Fig. 3). Bilateral symmetry is shown, each side having nine clearly distinguishable medial finger-like arborizations. The three anterior ones lie in the metathoracic ganglion while the six posterior ones reflect the segmentation of the fused abdominal ganglia. Although most sensory projections appear to be strictly ipsilateral, some in fact do project to the contralateral side. The general shape of the sensory projections (Fig. 4) is similar in all of the species studied.

Most sensory fibers form an intermediate neuropile that extends the length of the metathoracic-abdominal ganglionic complex (Figs. 3, 5, 7). From the nerve root 


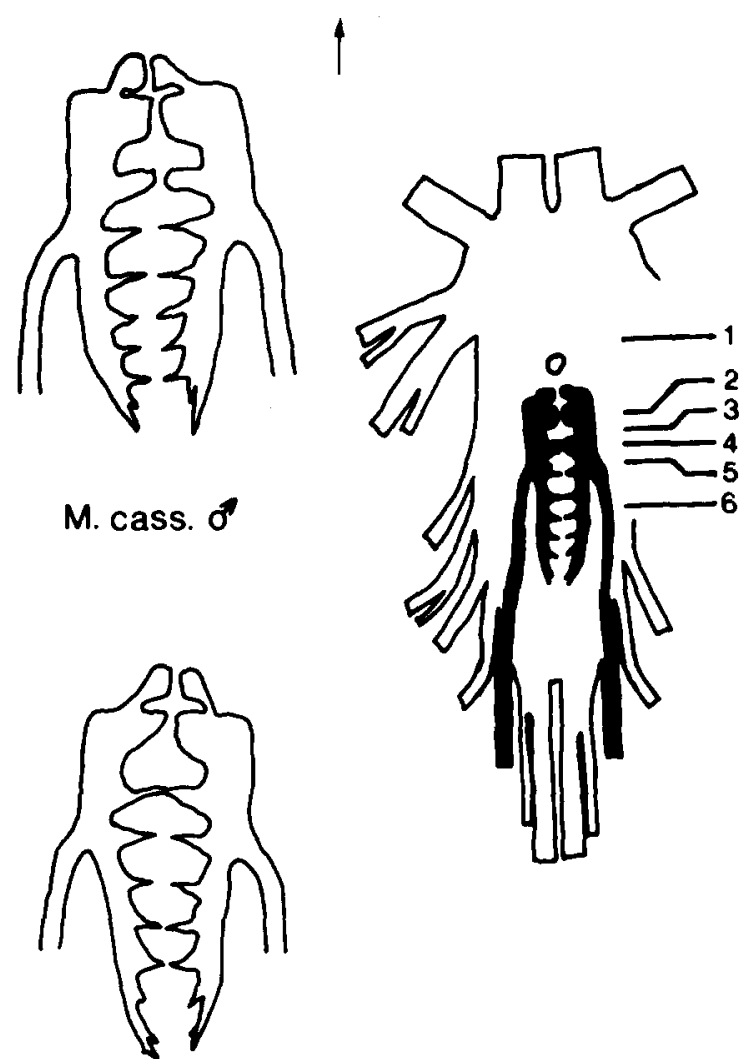

\section{M. septendecula ơ}

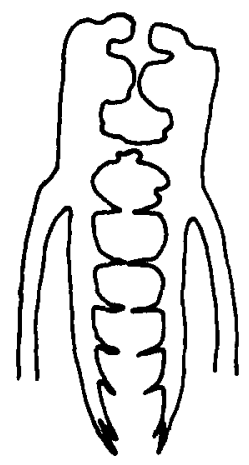

M. sept. $q$

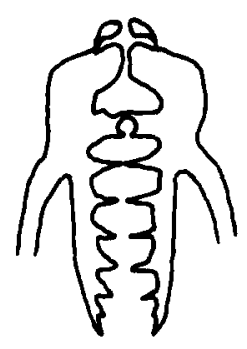

Fig. 4. General comparison of the sensory projections from the auditory nerve among species and sexes of 17 -year cicadas. Numbers $1-6$ refer to the planes of the sections shown in Fig. 5. Arrow indicates anterior

one bundle projects ventrally in the area of the abdominal complex showing a ventro-medial metameric organization; another bundle runs anteriorly sending ventral projections deep into the metathoracic part of the ganglionic complex (Figs. 6,$7 ; v p$ ). A bundle containing about 10 fibers courses anteriorly through the metathoracic part of the complex, finally projecting ipsilaterally into ventral neuropile of the mesothoracic ganglion (Figs. 6,7;ap). Some of these fibers also project at least as far as the prothoracic ganglion, but could not be studied in detail there. Single fibers were observed to project into both metathoracic and abdominal parts of the ganglionic complex, but because of the impregnation of the dense intermediate neuropile these could not be studied individually.

\section{The Timbal Motor Neuron}

The most prominent structure with an axon in the auditory nerve and arborizations in the metathoracic-abdominal ganglionic complex of male cicadas is the large 

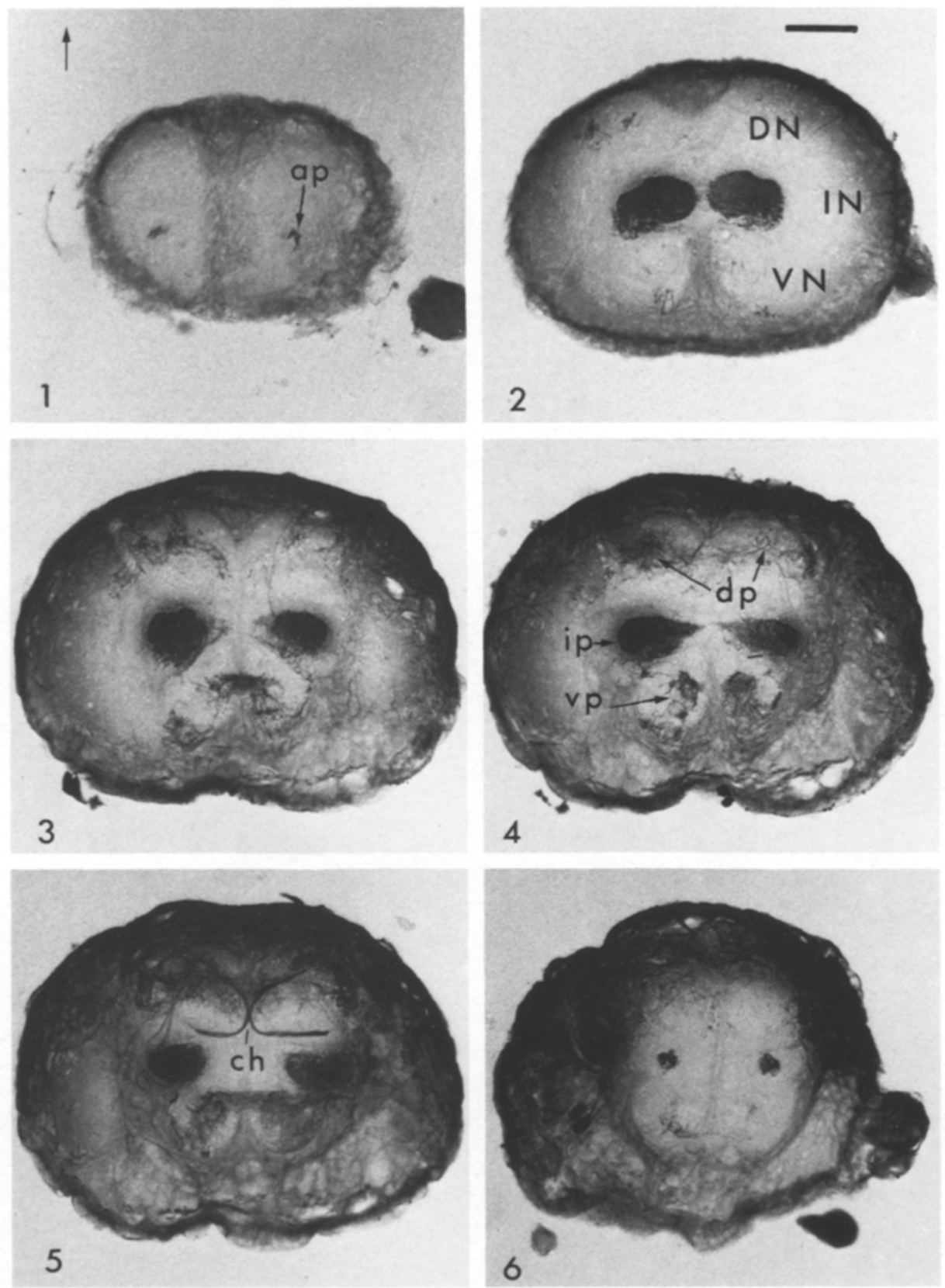

Fig. 5. Transverse sections (see Fig. 4 for the location of each section) from the meso- (l) and metathoracic-abdominal (2-6) ganglia of a male $M$. septendecim, showing the distribution of auditory nerve sensory fibers. Labels: $c h$ chiasma; $D N$ dorsal neuropile; $d p$ dorsal projections; $I N$ intermediate neuropile; ip intermediate projections; $V N$ ventral neuropile; $v p$ ventral projections; other labels as in previous figures. Scale: $100 \mu \mathrm{m}$. Arrow indicates dorsal 


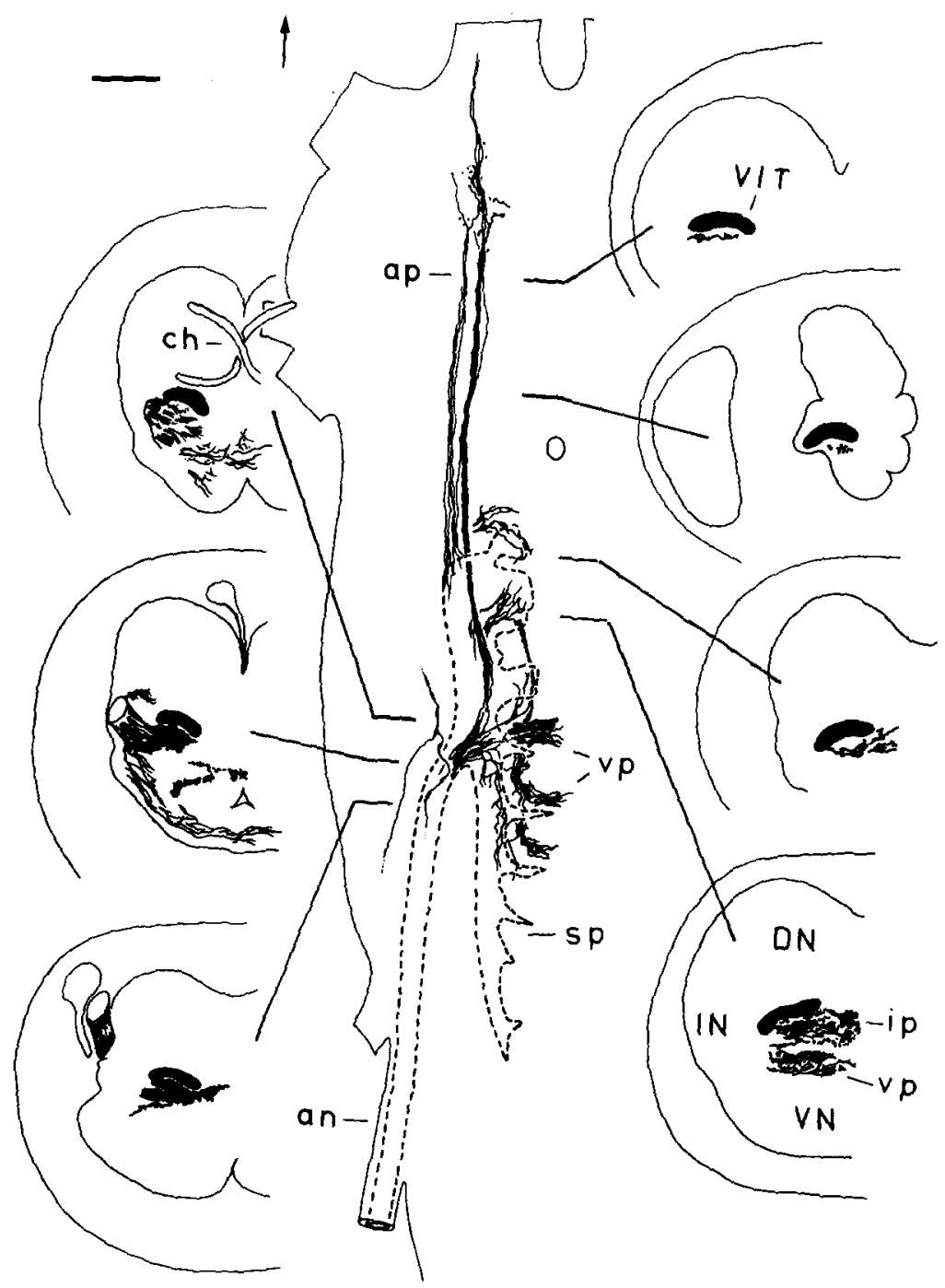

Fig. 6. Center: Reconstruction from horizontal sections showing in detail the ventral $(v p)$ and anterior (ap) projections from the auditory nerve. Left and right: Reconstructions of transverse sections showing the position of the sensory projections relative to the ventral intermediate tract (VIT). Labels: $s p$ sensory projections outlined in the intermediate neuropile; other labels as in previous figures. Scale: $100 \mu \mathrm{m}$. Arrow indicates anterior (horizontal sections) and dorsal (transverse sections)

timbal motor neuron (Fig. 8), first described anatomically in C. saundersii by Simmons (1977). There is a bilaterally symmetrical pair (Fig. 8b), each innervating the timbal muscle contralateral to the cell body position.

Dorsally in the ganglionic complex, the auditory nerve is composed of two roots (Fig. 8a; $d r, v r$ ), one containing afferent elements and the other efferents. The afferent bundle runs ventrally to arborize in intermediate and ventral neuropiles, 


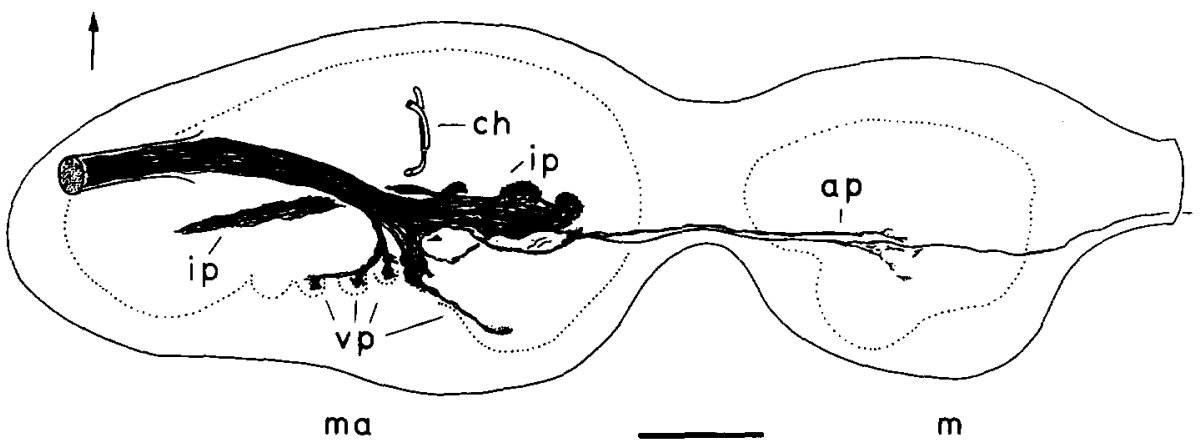

Fig. 7. Reconstruction of the sensory projections from the auditory nerve, viewed sagittally. Note the metamerism of the ventral neuropile. Labels as in previous figures. Scale: $200 \mu \mathrm{m}$. Arrow indicates dorsal
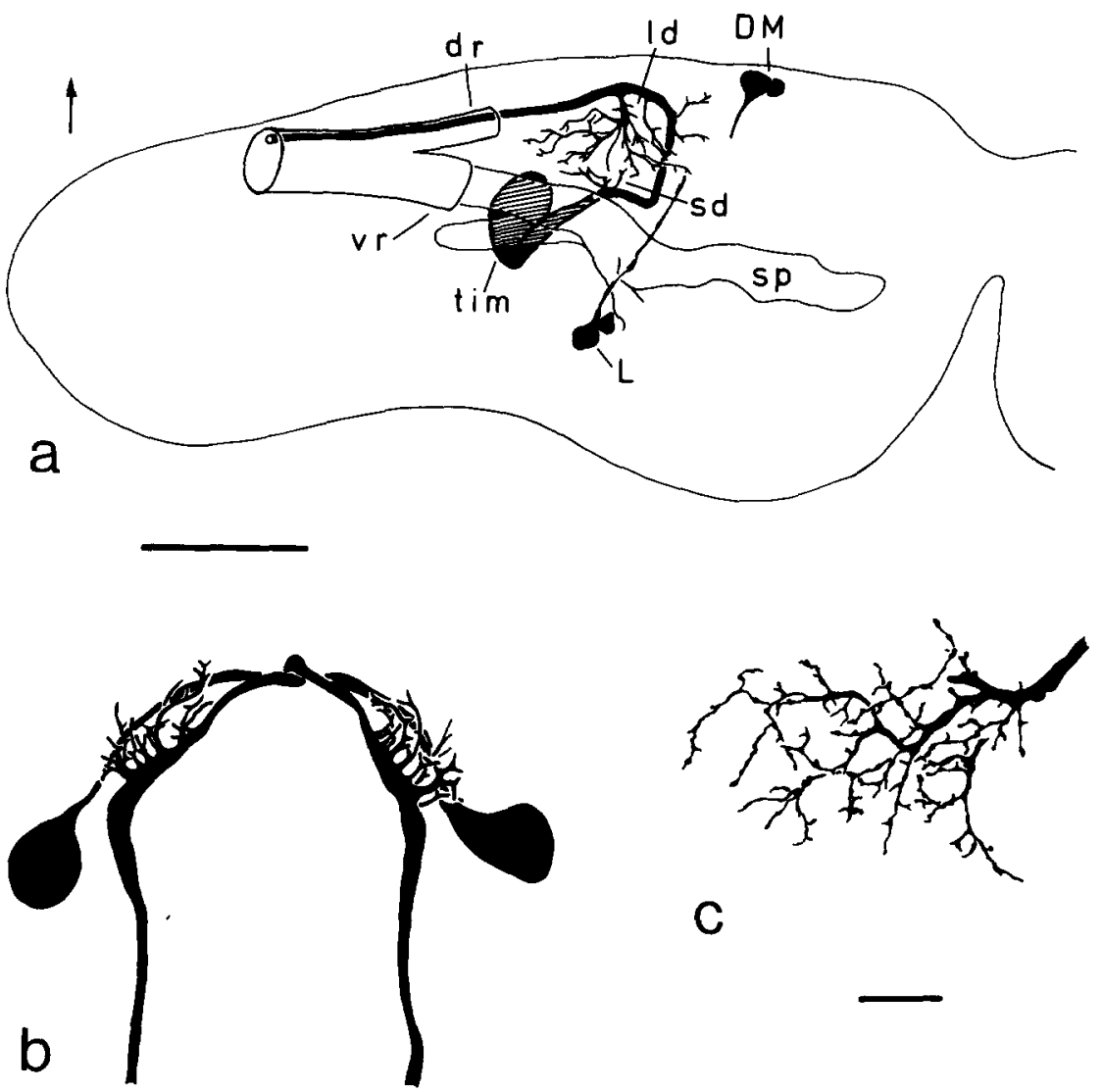

C

Fig. 8. Features of the timbal motor neuron ( $t$ im) within the metathoracic-abdominal ganglionic complex. a A sagittal view showing the motor neuron (here from a female $M$. cassini) with its large (ld) and small $(s d)$ dendritic regions. Other labels: $D M$ dorso-medial cell bodies; $d r$ dorsal root of the auditory nerve; $L$ lateral cell bodies; $v r$ ventral root of the auditory nerve. $\mathbf{b} A$ horizontal reconstruction of the timbal motor neuron pair in a male $M$. septendecim (viewed dorsally). c A small branch in the large dendritic region of the timbal motor neuron magnified to show the extent of arborization. Scale: $a$ and $b$ $200 \mu \mathrm{m}$ : c $20 \mu \mathrm{m}$. Arrow indicates dorsal in a and anterior in b 
D.W. Wohlers et al.
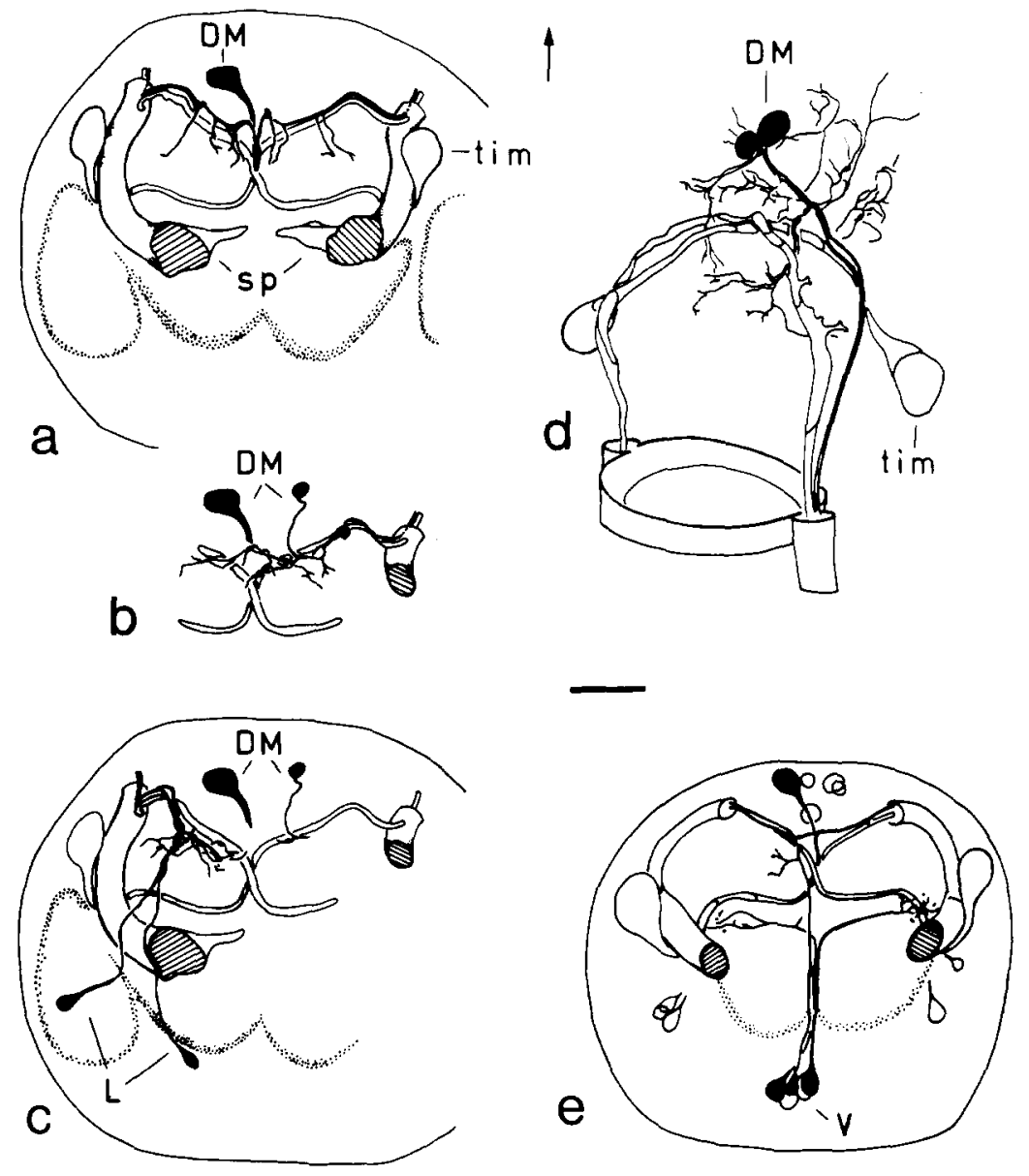

Fig. 9. Efferent elements within the metathoracic-abdominal ganglionic complex which are associated with the auditory nerve in $M$. septendecim males. a-c Reconstructions from transverse sections of one animal. d A slightly oblique horizontal reconstruction from a different animal. e A reconstruction from transverse sections of yet another animal. Labels as in previous figures. Scale: $100 \mu \mathrm{m}$. Arrow indicates dorsal (anterior in the case of $d$ )

while the efferent bundle runs more dorsally and contains several different elements, including the timbal motor axon.

Most efferent elements could not be classified in terms of ganglionic origin (metathoracic or abdominal). However, the large timbal motor neuron (axon diameter $20 \mu \mathrm{m}$ ) appears to be an abdominal structure with a large dendritic region located dorso-lateral and ipsilateral to the axon (Fig. 8). The cell body is located on the contralateral side in a more medio-lateral position and wraps itself around the afferent bundle from the auditory nerve on that side. In projecting across the midline the two axons come into close contact with one another in the medial position and then course ventrally together before turning laterally away from each other (Figs. $5 \mathrm{ch}, 8,9$ ). This "cross-over" point marks the anterior border to the 


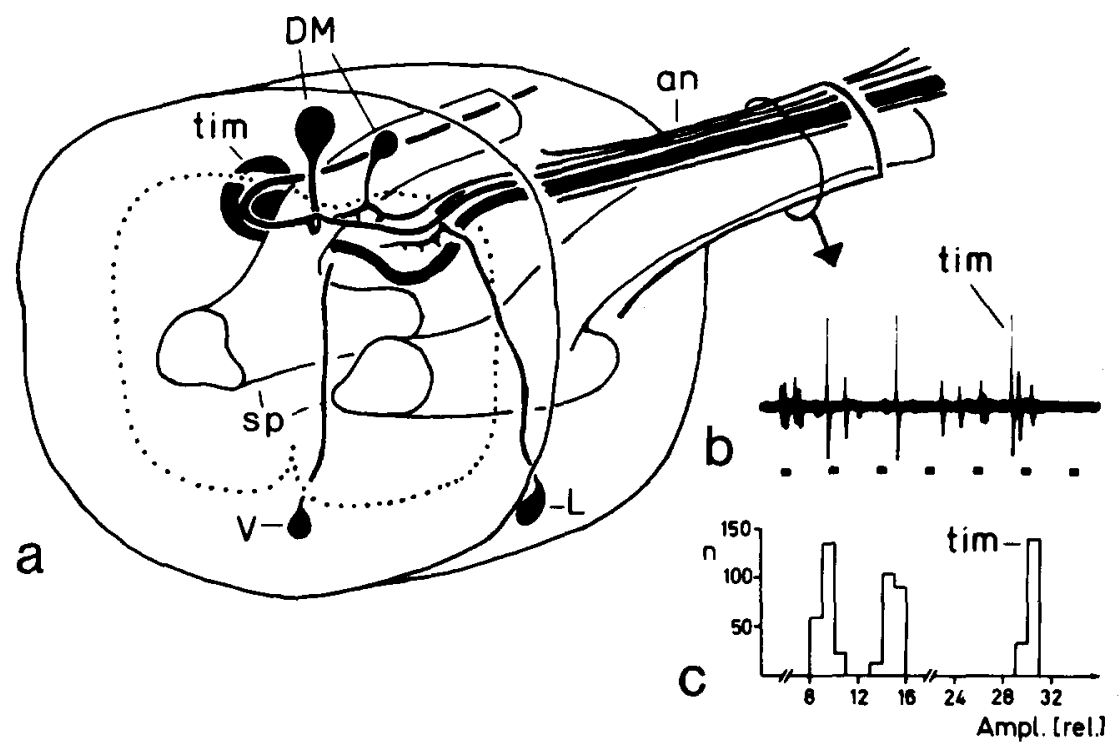

Fig. 10. a An oblique schematic drawing of the metathoracic-abdominal ganglionic complex (viewed anteriorly) showing the main components of the auditory nerve including the intermediate sensory neuropile and several efferent neuron types. Labels as in previous figures. $\mathbf{b}$ Hook-electrode recording showing spike activity from at least three different motor units, the spikes with the highest amplitude coming from the timbal motor neuron $(\mathrm{tim})$. The auditory nerve was cut peripheral to the electrode to eliminate afferent activity. Time scale $20 \mathrm{msec}$. $\mathrm{c}$ An histogram of spike amplitudes from a continuous hook-electrode recording of the proximal auditory nerve as shown in b. Abscissa: relative amplitude of spikes. Ordinate: number of spikes of a given amplitude. The histogram shows three distinctly different spike amplitudes, the highest amplitude coming from the timbal motor neuron ( $\mathrm{tim}$ )

abdominal portion of the ganglionic complex. There is also a small dendritic region on the cell-body side (Fig. 8a, sd) which overlaps the large dendritic region of the mirror-image timbal motor neuron. In addition, there is indication of arborization at the cross-over point. These have not been mentioned in earlier work.

Females have an homologous motor neuron. It is reduced in size and dendritic elaboration in M. septendecim and M. septendecula. However, in females of $M$. cassini (Fig. 8a) and O. rimosa it could not be distinguished from that found in males.

\section{Other Efferent Fibers Associated with the Auditory Nerve}

Several other types of efferent neurons also have axons in the auditory nerve. One has cell bodies located on the dorso-medial surface of the metathoracic part of the ganglionic complex (Fig.9d, DM; Fig. 8a); they have dorsal dendritic arborizations in both hemispheres of metathoracic and abdominal portions. Their axons leave the ganglionic complex through the auditory nerve contralateral to the cell body position, although the cell bodies sometimes appear to lie directly on the midline. As many as four cells of this type have been observed coursing in each auditory nerve. 
Two more neurons with dorsal cell bodies located just posterior to the "crossover" position of the timbal motor neurons were also stained from the auditory nerve (Fig. $9 \mathrm{a}$ and $\mathrm{b}, D M$ ). The larger of the two (Fig. 9a) has a medially positioned cell body with dendrites in both abdominal ganglionic hemispheres, and a pair of axons, one coursing to each auditory nerve. The smaller cell (Fig. 9 b) also has a dorsal cell body which is positioned a little more laterally. It has dendrites in both abdominal ganglionic hemispheres and a single ipsilaterally-projecting axon.

There is a third cell type with lateral cell bodies and dorsal ipsilateral dendrites in the abdominal portion of the ganglionic complex (Fig. 9c, $L$ ). Several of these have been found on each side. A fourth cell type with medio-ventral cell bodies (Fig. 9e, V) resembles the common inhibitors described by Burrows (1973) for Schistocerca gregaria. Cells of this type also appear to arise from abdominal portions of the ganglionic complex. Some have dorsal dendritic processes lying ipsilateral to the axon. Others have more lateral dendritic processes.

The anatomical finding of several efferent fibers within the auditory nerve is substantiated by hook electrode recordings from the proximal stump of this nerve (Fig. 10). Such recordings show several easily distinguished efferent neurons.

\section{Central Projections of Sensory Fibers in the Tensor Nerve}

Projections of sensory fibers from the tensor nerve also reveal a metameric organization within the metathoracic-abdominal ganglionic complex (Fig. $11 \mathrm{a}, t n$ ). When comparing this structure to that of the auditory nerve (Fig. 11a, an), the tensor fibers also show finger-like medial projections to the intermediate neuropile. A few fibers appear to project contralaterally, though most remain ipsilateral to the nerve root. The main sensory neuropile from the tensor nerve lies ventral to that from the auditory nerve with some spatial overlap, and no fibers were observed to project from the tensor nerve to areas of ventral neuropile within the ganglionic complex. A few fibers leaving the tensor nerve root do course to the mesothoracic ganglion and further. The projections of these fibers in the mesothoracic ganglion appear to be more diffuse, reaching more laterally than those arising from the auditory nerve (compare Fig. 11 a, $a p$ left and right). The sensory fibers in the tensor nerve probably arise from the two chordotonal organs described by Young (1975). In addition, a contribution from body hairs may exist (see Simmons and Young, 1978).

\section{Efferent Fibers Associated with the Tensor Nerve}

There are several types of efferent neurons distinguished by their cell-body position (Fig. 11 e). Two of these have ventral cell bodies, one medially and the other more laterally positioned (Fig. 11 b). Both have ipsilaterally projecting axons and are bilaterally represented. They exhibit branching in both hemispheres of the metathoracic and abdominal portions of the ganglionic complex.

Other neurons with lateral cell bodies were also found. Their branching pattern is mainly ipsilateral and is less extensive than that of the ventral cells (Fig. 11c). 

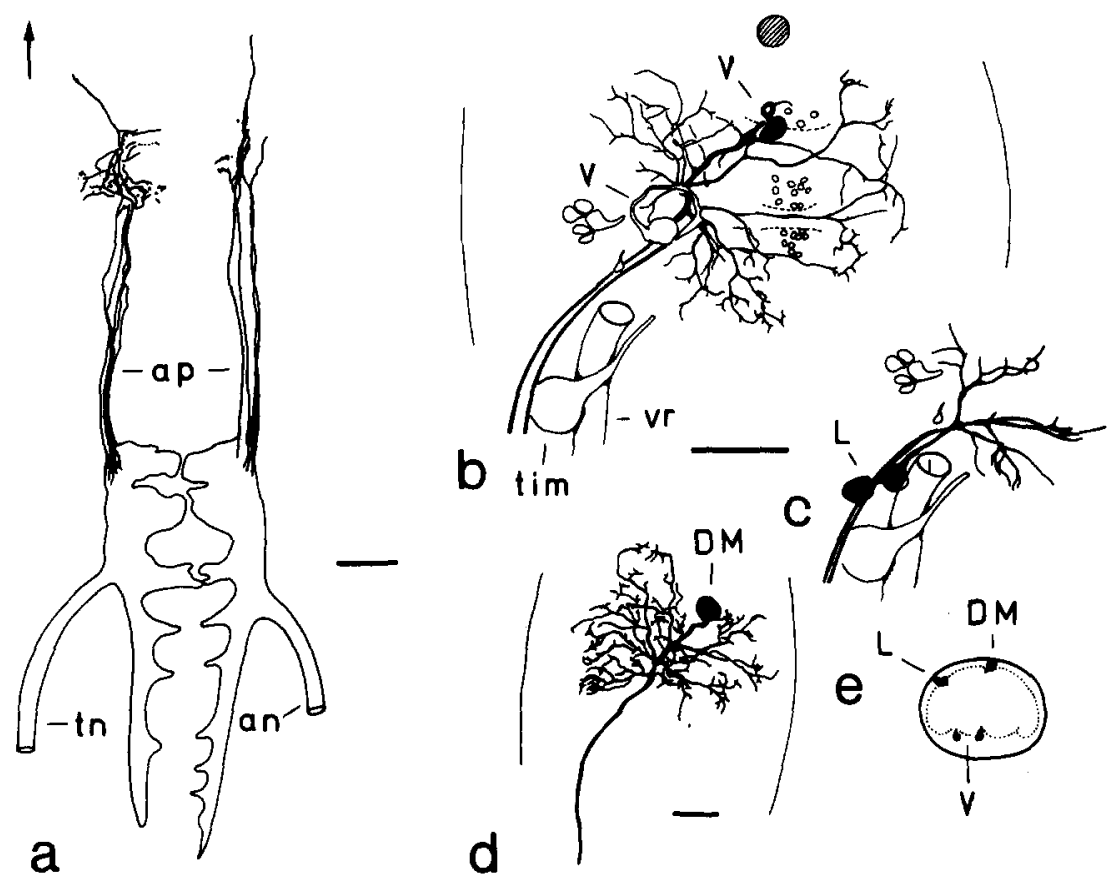

Fig. 11. Horizontal reconstructions of elements in the metathoracic-abdominal ganglionic complex which are associated with the tensor nerve. $a$ The general shape of the sensory neuropile from the tensor nerve (left) compared to that from the auditory nerve (right), both showing bundles (ap) projecting into the mesothoracic ganglion. $b-\mathbf{d}$ Efferent elements from the tensor nerve (for details see text). $\mathrm{e}$ Schematic transverse section showing the location of cell bodies from elements drawn in b-d. Scale: $100 \mu \mathrm{m}$. Arrow indicates anterior

There are several cells of this type, all appearing to arise from the abdominal portion of the ganglionic complex.

There is also a large and elaborate neuron with medio-dorsal cell body and profuse dorsal branching on both sides of the midline (Fig. 11d). The exact number of elements of this type is not known, although three cell bodies have been stained on occasion.

\section{Discussion}

The metathoracic-abdominal ganglionic complex of the cicada has a basic tripartite organization (Zawarzin, 1924). On structural grounds alone we can discern an upper motor region, a lower non-motor keel which can be further subdivided into intermediate and ventral neuropile regions, and a core region (Williams in prep.) These are conservative features of all insect ganglia and are a reflection of the set of relationships individually identifiable neurons have to each other.

\section{Afferent Elements}

Various Orthopterans, including crickets (Rehbein, 1973; Eibl, 1976; Popov et al., 1978; Eibl and Huber, 1979; Esch et al., in prep.), Tettigonids (Kalmring 
et al., 1978), and Acridids (Rehbein et al., 1974), have distinct intermediate auditory neuropiles, projections being purely ipsilateral. Cicadas (Homoptera) show the same intermediate neuropilar structure from afferents of both the auditory and tensor nerves (see Figs. 3, 5,11a). Therefore, a "formanalytic homology" (Jacobshagen, 1925) is apparent not only among species, but also among orders of insects.

By comparing the projection areas of sensory afferents (from leg nerves) into the pro-, meso-, and metathoracic ganglia of crickets, Eibl (1976) shows that even though sensory structures vary between segments, there is nevertheless a serial homology of intermediate sensory neuropile in all three ganglia (Eibl and Huber, 1979). In the metathoracic-abdominal ganglionic complex of cicadas there is also a serially metameric organization of sensory neuropiles arising from individual sensory structures. It is evident therefore, that at least the sensory part of insect nervous systems contributes to highly-ordered structural and functional "layering" (Williams, in prep.).

As already mentioned, projections of auditory afferents in Orthopterans are intermediate, and Hustert (1978) shows that chordotonal proprioceptors are also represented in intermediate neuropile. Studies of auditory organs (Michel, 1975) and chordotonal organs of cicada (Young, 1975) reveal that the auditory nerve receives on the order of 1300 axons from the auditory organ and 500 axons from the detensor tympani-chordotonal organ (Fig. 2, left).

Our auditory nerve fills show a high concentration of sensory arborization within the intermediate neuropile. On a comparative basis we can say that this concentration comes from auditory and chordotonal receptors. On the other hand, sensory cells from head and body hairs are known to project into ventral neuropile (Honegger, 1977; Hustert, 1978; Tyrer et al., 1979). The relatively few sensory fibers from the auditory nerve projecting into ventral neuropile in cicadas probably represent body hairs (see Fig. 2, left).

Simmons and Young (1978) showed that the majority of sensory elements in the tensor nerve originate from the timbal and tensor chordotonal organs. Our tensor fills reveal an intermediate neuropilar structure which is similar to that found in auditory fills (see Fig. 11a), showing a chordotonal projection to this region.

Since Hustert (1978) found no chordotonal organ in locusts and crickets without at least a few plurisegmental fibers, we propose that the through-fibers to the meso- and prothoracic ganglia from both the tensor and auditory nerves in our cicada preparations are also chordotonal in origin.

\section{Efferent Elements}

The variety of efferent elements in the metathoracic-abdominal ganglionic complex which have axons in the auditory nerve (see Fig. 10) can be correlated to studies of the periphery. In all species studied here, and as shown by Young (1975) for C. saundersii, both the detensor tympani and timbal muscles are innervated by peripheral branches of the auditory nerve (see Fig. 2, left). The large timbal motor neuron is, however, the only element which could be anatomically identified both centrally and peripherally. In C. saundersii, Simmons (1977) described the large dendritic region contralateral to the cell body. In addition, we have shown a small ipsilateral dendritic region which spatially overlaps the large dendritic region of the 
opposite paired member. Its functional significance is not known; however, one must return to the early work of Hagiwara and Watanabe (1956) where they proposed a mechanism of coupling between the two timbal motor neurons to control the alternation of firing. Such a coupling could occur between the large and small dendritic regions as well as at the cross-over point.

In females there is no sign of a timbal muscle (Pringle, 1957; Moore, unpublished results). The presence of an elaborate motor neuron, which is similar in size, shape, and position (within the ganglionic complex), is therefore very surprising. Its function can be worked out after its peripheral innervation has been determined; this work is in progress.

The timbal muscle of male cicadas has been a classic example of a muscle innervated by a single motor neuron (Pringle, 1957: Simmons, 1977). We have found that there are at least three additional axons invading the timbal muscle of male 17-year cicadas (Fig. 2, inset). The structure of these elements has not been established, but there may indeed be a more typical polyneural innervation of the timbal muscle.

Independent of cell-body position, efferent neurons having axons in either the auditory or tensor nerve arborize in the dorsal motor region of the metathoracicabdominal ganglionic complex. From comparative studies, the neurons with ventral cell bodies may include common inhibitors (Burrows, 1973). The elements having lateral cell bodies are most likely fast and slow motor neurons.

The axons of neurons with dorso-medial cell bodies may be ipsi-, contra-, or bilateral in distribution. One of these cells is similar in structure to the DUM cells of the locust (Plotnikova, 1969; Crossman et al., 1971; Hoyle, et al., 1974; Goodman and Spitzer, 1979). Whether this cell contains octopamine and is functionally similar to the DUM cells (Evans and O'Shea, 1978) has not yet been established in cicadas.

These studies of the central projections of afferent and efferent elements which are a part of the sound communication system in cicada, reveal a complexity making it impossible at present to give further suggestions about neuronal connectivity. This goal can only be reached through detailed studies of clearly defined afferent structures and through identification of central nervous components to which they project, some studies of which have already been initiated (Huber et al., in press, 1980).

Acknowledgements. The authors are grateful to the Max-Planck-Socicty and The University of Michigan for financing the research in the USA, and to the Museum of Zoology and Division of Biological Sciences at the University of Michigan for providing equipment and laboratory facilities. We are also grateful to Ms. H. Bamberg for her assistance with photographic work

\section{References}

Alexander, R.D.: Acoustical communication in arthropods. Ann. Rev. Entomol. 12, 495-526 (1967) Bacon, J.P., Altman, J.S.: A silver intensification method for cobalt-filled neurones in wholemount preparations. Brain Res. 138, 359-363 (1977)

Burrows, M.: Physiological and morphological properties of the metathoracic common inhibitory neuron of the locust. J. Comp. Physiol. 82, 59-78 (1973)

Crossman. A.R., Kcrkut, G.A., Pitman, R.M., Walker, R.I.: Electrically excitable nerve cell bodics in the 
central ganglia of two insect species Periplaneta americana and Schistocerca gregaria. Investigation of cell geometry and morphology by intracellular dye injection. Comp. Biochem. Physiol. [A] 40, 579-594 (1971)

Eibl, E.: Morphologische und neuroanatomische Untersuchungen zur Sinnesorganausstattung der proximalen Tibienabschnitte und ihrer zentralen Projektionen bei Grillen. Köln: Dissertation (1976)

Eibl, E., Huber, F.: Central projections of tibial sensory fibers within the three thoracic ganglia of crickets (Gryllus campestris L., Gryllus bimaculatus DeGeer). Zoomorph. 92, 1-17 (1979)

Esch, H., Huber, F., Wohlers, D.: Primary auditory neurons in Crickets: Physiology and central projections. In preparation (1980)

Evans, P.D., O'Shea, M.: The identification of an octopaminergic neurone and the modulation of a myogenic rhythm in the locust. J. Exp. Biol. 73, 235-260 (1978)

Fielden, A.: Transmission through the last abdominal ganglion of the dragonfly nymph, Anax imperator. J. Exp. Biol. 37, 832-844 (1960)

Goodman, C.S., Spitzer, N.C.: Embryonic development of identified neurones: differentiation from neuroblast to neuron. Nature 280, 208-214 (1979)

Hagiwara, S., Watanabe, A.: Discharges in motorneurons of cicada. J. Cell Physiol. 47, 415-428 (1956)

Honegger, H.-W.: Interommatidial hair receptor axons extending into the ventral nerve cord in the cricket Gryllus campestris. Cell Tissue Res. 182, 281-285 (1977)

Hoyle, G., Dagan, D., Moberly, B., Colquhoun, W.: Dorsal unpaired median insect neurons make neurosecretory endings on skeletal muscle. J. Exp. Zool. 187, 159-165 (1974)

Huber, F., Wohlers, D.W., Moore, T.E.: Auditory receptor and interneurone responses to natural sounds in several species of cicadas. Physiol. Entomology, in press (1980)

Hustert, R.: Segmental and interganglionic projections from primary fibers of insect mechanoreceptors. Cell Tissue Res. 194, 337-351 (1978)

Jacobshagen, E.: Allgemeine vergleichende Formlehre der Tiere. Leipzig: Klinkhardt (1925)

Kalmring, K., Lewis, B., Eichendorf, A.: The physiological characteristics of the primary sensory neurons of the complex tibial organ of Decticus verrucivorus L. (Orthoptera, Tettigonioidae). J. Comp. Physiol. 127, 109-121 (1978)

Michel, K.: Das Tympanalorgan von Cicada orni L. (Cicadina, Homoptera). Eine licht- und elektronenmikroskopische Untersuchung. Zoomorph. 82, 63-78 (1975)

O'Shea, M., Rowell, C.H.F., Williams, J.L.D.: The anatomy of a locust visual interneurone; the descending contralateral movement detector. J. Exp. Biol. 60, 1-12 (1974)

Plotnikova, S.I.: Effectory neurons with several axons in the ventral nerve cord of Locusta migratoria. I. Evol. Biochem. Physiol. 5, 339-341 (1969)

Popov, A.V., Markovich, A.M., Andjan, A.S.: Auditory interneurons in the prothoracic ganglion of the cricket, Gryllus bimaculatus DeGeer. I. The large segmental auditory neuron (LSAN). J. comp. Physiol. 126, 183-192 (1978)

Pringle, J.W.S.: The mechanism of the myogenic rhythm of certain insect striated muscles. J. Physiol. 124, 269-291 (1954)

Pringle, J.W.S.: The structure and evolution of the organs of sound-production in cicadas. Proc. Linn. Soc. Lond. 167, 144-159 (1957)

Rehbein, H.G.: Experimentell-anatomische Untersuchungen über den Verlauf der Tympanalnervenfasern im Bauchmark von Feldheuschrecken, Laubheuschrecken, und Grillen. Verh. dtsch. Zool. Ges. 66, 184-189 (1973)

Rehbein, H.G., Kalmring, K., Römer, H.: Structure and function of acoustic neurons in the thoracic ventral nerve cord in Locusta migratoria (Acrididae). J. Comp. Physiol. 95, 263-280 (1974)

Simmons, P.J.: Neuronal generation of singing in a cicada. Nature 270, 243-245 (1977)

Simmons, P.J., Young, D.: The tymbal mechanism and song patterns of the bladder cicada, Cystosoma saundersii. J. Exp. Biol. 76, 27-45 (1978)

Tyrer, N.M., Bacon, J.P., Davis, C.A.: Primary sensory projections from the wind-sensitive head hairs of the locust Schistocerca gregaria. Cell Tissue Res. in press 1979

Vasvary, L.M.: Musculature and nervous system of the thorax, of the sound mechanism, and of a typical pregenital abdominal segment of the male of the annual cicada, Tibicen chloromera (Walker) (Homoptera: Cicadidae). N.Y. Entom. Soc. 74, 2-55 (1966)

Vogel, R.: Über ein tympanales Sinnesorgan, das mutmaßliche Hörorgan der Singzikaden. Z. ges. Anat. I. Z. Anat. EntwGesch. 67, 190-231 (1923) 
Williams, J.L.D.: Anatomical studies of the insect central nervous system: An introduction to the longitudinal fibre tracts in the thoracic ganglia of the adult cricket. In preparation

Young, D.: Neuromuscular mechanism of sound production in Australian cicadas. J. Comp. Physiol. 79, 343-362 (1972)

Young, D.: Chordotonal organs associated with the sound producing apparatus of cicadas (Insecta, Homoptera). Z. Morph. Tiere 81, 111-135 (1975)

Young, D., Hill, K.G.: Structure and function of the auditory system of the cicada, Cystosoma saundersii. J. Comp. Physiol. 117, 23-45 (1977)

Zawarzin, A.: Zur Morphologie der Nervenzentren. Das Bauchmark der Insekten. Ein Beitrag zur vergleichenden Histologie (Histologische Studien über Insekten. VI). Z. Wiss. Zool. 122, 323-424 (1924)

Accepted August 22, 1979 